\title{
Comparison of bacterial communities in leachate from decomposing bovine carcasses
}

\author{
Seung Hak Yang ${ }^{1, *}$, Hee Kwon Ahn², Bong Soo Kim³, Sun Sik Chang', Ki Yong Chung ${ }^{1}$, \\ Eun Mi Lee ${ }^{1}$, Kwang Seok Ki', and Eung Gi Kwon ${ }^{1}$
}

\author{
* Corresponding Author: Seung Hak Yang \\ Tel: +82-33-330-0612, Fax: +82-33-330-0660, \\ E-mail: y64h@korea.kr \\ 'Hanwoo Research Institute, National Institute of \\ Animal Science, Rural Development Administration, \\ Pyeongchang 25340, Korea \\ 2 Department of Animal Biosystems Science, \\ Chungnam National University, Daejeon 34134, \\ Korea \\ ${ }^{3}$ Department of Life Science, Hallym University, \\ Chuncheon 24252, Korea
}

Submitted Jul 26, 2017; Revised Sept 8, 2017; Accepted Sept 15, 2017
Objective: Burial is associated with environmental effects such as the contamination of ground or surface water with biological materials generated during the decomposition process. Therefore, bacterial communities in leachates originating from the decomposing bovine carcasses were investigated.

Methods: To understand the process of bovine (Hanwoo) carcass decomposition, we simulated burial using a lab-scale reactor with a volume of $5.15 \mathrm{~m}^{3}$. Leachate samples from 3 carcasses were collected using a peristaltic pump once a month for a period of 5 months, and bacterial communities in samples were identified by pyrosequencing of the $16 \mathrm{~S}$ rRNA gene.

Results: We obtained a total of 110,442 reads from the triplicate samples of various sampling time points (total of 15 samples), and found that the phylum Firmicutes was dominant at most sampling times. Differences in the bacterial communities at the various time points were observed among the triplicate samples. The bacterial communities sampled at 4 months showed the most different compositions. The genera Pseudomonas and Psychrobacter in the phylum Proteobacteria were dominant in all of the samples obtained after 3 months. Bacillaceae, Clostridium, and Clostridiales were found to be predominant after 4 months in the leachate from one carcass, whereas Planococcaceae was found to be a dominant in samples obtained at the first and second months from the other two carcasses. The results showed that potentially pathogenic microbes such as Clostridium derived from bovine leachate could dominate the soil environment of a burial site.

Conclusion: Our results indicated that the composition of bacterial communities in leachates of a decomposing bovine shifted continuously during the experimental period, with significant changes detected after 4 months of burial.

Keywords: Hanwoo; Decomposition; Leachate; Bacterial Community; Firmicutes; Pyrosequencing

\section{INTRODUCTION}

Epidemics in Artiodactyla such as foot and mouth disease (FMD) have led to the death of thousands of livestock animals. The FMD outbreak of 2010 in South Korea led to almost 3.5 million animal deaths with the majority of carcasses disposed through burial [1]. Burial is a common disposal procedure for the management of large numbers of deceased livestock animals, although other disposal methods such as incineration, composting, and rendering are recommended to prevent the spread of infectious diseases. Pathogens released from an animal carcass and health problems in residents living near landfills where these carcasses are disposed are a public health concern [2]. In addition, there have been a few reports of drinking water contamination with enteric pathogens following the burial of animal carcasses, and some infectious materials such as anthrax spores or prions can remain within the soil after carcass decomposition $[3,4]$. 
Carcass decomposition in burial sites can be affected by various factors such as the inner temperature, humidity, $\mathrm{pH}$, and aeration of the body [5-7]. These environmental factors related to carcass decomposition might affect microbial metabolic activity at the burial site, although the metabolism of microorganisms present during carcass degradation has never been assessed.

Leachates derived from the decomposition of animal carcasses contain organic intermediates, volatile chemicals, and decomposing organisms [8]. The high organic content of the leachate can cause extreme changes in aquifer ecology and microbial communities downstream of landfills [8]. In addition, leachates from the decomposition of bovine carcasses can contaminate the area around the burial site with ruminal microorganisms. Environmental and sanitary or food safety hazards posed by leachates have not been adequately evaluated, despite recognition of these risks.

Microbial communities are essential to maintaining soil quality because of their involvement in organic matter dynamics, nutrient cycling, and decomposition [9]. Keener et al reported that carcasses are degraded anaerobically by bacteria inside the carcass and aerobically by bacteria on the outer surface of the carcass [10]. Therefore, the rate of decomposition of a carcass correlates with environmental factors such as the availability of oxygen.

To date, only a few studies have examined the characteristics of uncultured microbial communities in burial sites [11,12]. The presence of uncultivable bacteria has been demonstrated by polymerase chain reaction-denaturing gradient gel electrophoresis (PCR-DGGE), although these studies were limited by low detection rates of microbes in landfill leachate plumes [11]. Next-generation sequencing techniques such as bar-coded pyrosequencing can be used to elucidate microbial community dynamics at a much higher resolution than was previously possible. In addition, the large dataset generated by pyrosequencing makes it possible to detect rare microbes and to perform phylogenetic comparisons of microbes living in a specific environment [13]. This study was conducted using pyrosequencing to clarify the cascade of microbial communities through time in leachates from decomposing bovine carcasses.

\section{MATERIALS AND METHODS}

\section{Lab-scale reactor}

Lab-scale reactors were designed based on an animal mortality mass burial protocol that was developed by the Korean Ministry for Food, Agriculture, Forestry, and Fisheries. Care of animals was in accordance with the Guide for the Care and Use of Experimental Animals (IACUC number: 2012-C-056). To simulate decomposition of bovine carcasses in real burial sites, the reactors were made with a volume of $5.15 \mathrm{~m}^{3}$. The average weight of Hanwoo (Bos taurus coreanae) used in this study was 430.17 $\pm 21.48 \mathrm{~kg}$. These carcasses were placed on top of soil and quicklime $(3.75 \mathrm{~cm}$ soil $+0.37 \mathrm{~cm}$ quicklime $+3.75 \mathrm{~cm}$ soil $)$ and also covered with layers of the same. To control the bacterial decomposition rate of the carcasses, the reactors were held at a constant temperature of $35^{\circ} \mathrm{C}$. Leachate from each reactor was collected once a month by a peristaltic pump. The samples collected during decomposition were stored at $-80^{\circ} \mathrm{C}$ for molecular analysis.

\section{Pyrosequencing}

Genomic DNA was extracted from leachate samples collected from three Hanwoo carcasses (A, B, and C) using a Fast DNA Spin Kit for Soil (MP Biomedicals, Santa Ana, CA, USA). The extracted DNA was purified using a PowerClean DNA Clean-Up Kit (Mobio, Carlsbad, CA, USA), and 16S rRNA (V1-V3 region) was amplified using fusion primers targeting bacteria [14]. A C1000 Touch thermal cycler (Bio-Rad, Hercules, CA, USA) was used to amplify DNA following previously described methods [14], and PCR products were confirmed to be $16 \mathrm{~S}$ rRNA by $2 \%$ agarose gel electrophoresis and purified using a QIAquick PCR Purification Kit (Qiagen, Valencia, CA, USA). The concentration of each amplicon was determined using a PicoGreen dsDNA Assay Kit (Invitrogen, Carlsbad, CA, USA) and pooled for multiplex sequencing. Pooled amplicons were purified using an AMPure bead kit (Agencourt Bioscience, Beverly, MA, USA), and then emulsion PCR was performed on sequencing beads. The beads recovered from emulsion PCR were deposited on a 454 Picotiter Plate and sequenced using a Roche/454 GS Junior system following the manufacturer's instructions.

\section{Analysis of pyrosequences}

The analysis of raw sequence files was performed as previously described $[14,15]$. Raw reads were sorted by unique barcodes, primer sequences were trimmed, and low quality reads (average quality score $<25$ or read length $<300 \mathrm{bp}$ ) were removed. Representative sequences in clusters of sequences were selected for sequencing error correction, and their taxonomic positions were identified by determining the highest pairwise similarity scores among the top five BLASTN hits in the EzTaxon-e database [16]. Chimeric sequences were detected by UCHIME [17]. Random subsampling was used to normalize the read numbers in each sample. Chaol, Shannon index, and Good's coverage indices were calculated at a 3\% dissimilarity level using Mothur [18]. The relationships between samples were investigated by principal coordinate analyses (PCoA) using Fast UniFrac distances [13]. Pyrosequencing reads obtained from this study were deposited in the EMBL SRA database under study accession number PRJ EB4428 (http://www.ebi.ac.uk/ena/data/view/PRJEB4428).

\section{RESULTS AND DISCUSSION}

Shifts in the bacterial communities of leachates from three bovine carcasses, sampled at different decomposition times, were investigated by pyrosequencing of the $16 \mathrm{~S}$ rRNA. Sequences obtained at each sampling time were analyzed and compared. Diversity 
indices, determined after normalization, are presented in Table 1. A total of 110,442 reads were obtained, and their average length was $466.1 \mathrm{bp}$. The normalized read number was 3,300 for each sample except sample C_1, which had a lower number of reads (2,541 reads) than other samples. Minimum and maximum coverage were $76 \%$ and $95 \%$, respectively. The numbers of observed operational taxonomic units (OTUs) varied at each sampling time. The highest number of OTUs was observed in samples from carcass A after 1 month (A_1), and the lowest number was observed in samples of Carcass $\mathrm{C}$ after 3 months (C_3). Shannon diversity indices for samples from carcass $\mathrm{B}$ and $\mathrm{C}$ were low until the third month, and they showed a further increase in the fourth month. In contrast, Shannon diversity indices for samples from carcass A fluctuated across the sampling times, as shown in Figure 1. These variations in bacterial diversity in leachates from three decomposing bovine carcasses indicated that changes in bacterial communities varied by individual.

Bacterial community compositions at each sampling time in leachates from the three carcasses were analyzed and compared at the phylum and genus levels and are shown in double pie charts (Figure 2). The phylum Firmicutes dominated (over $99 \%$ of total reads) the bacterial communities of carcasses $B$ and $C$ at each sampling time, except in the third month, even though the phyla Proteobacteria, Actinobacteria, and Firmicutes were predominant in the microbial communities in soil used in this study, representing $41.7 \%, 31.2 \%$, and $9.0 \%$ of bacterial sequences, respectively (data not shown). Proteobacteria was the dominant phylum in samples from the third month for carcasses B and C, and the phylum Bacteroidetes also showed an increase at that time. Bacteroidetes spp. are reported to play a role in the fermentation of polysaccharides and to use nitrogenous substances as their energy source [19]. The composition of phyla in the leachate sample from carcass $\mathrm{A}$ in the first month was different from the compo-

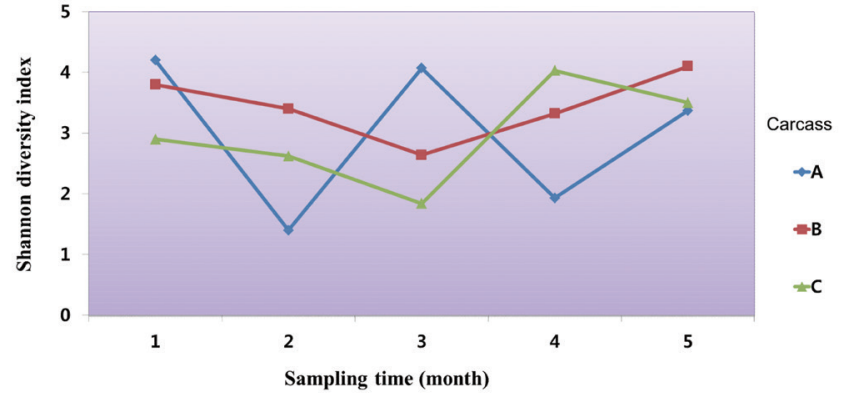

Figure 1. Rarefaction curve to estimate the diversity of taxa present in individual samples using the Shanon index.

sition of bacteria in the leachate from other carcasses. Firmicutes were reported to reduce large macromolecules such as proteins, complex fats, and polycarbohydrates to their building blocks (e.g., amino acids, complex fats, and monosugars) [20]. The proportion of bacteria that were Firmicutes was 79.9\%, and Chloroflexi and Proteobacteria represented over 5\% of the total reads. This difference generated unique changes of bacterial communities in leachate from carcass A. The phylum Proteobacteria comprises $\alpha$-Proteobacteria, $\beta$-Proteobacteria, $\gamma$-Proteobacteria, and $\delta$-Proteobacteria. Of these, $\gamma$-Proteobacteria are common in soil and are known to contribute to the decomposition of fats and carbohydrates $[21,22]$. Chloroflexi specializes in decomposing carbohydrates [23]. Proteobacteria were dominant $(80.5 \%$ of total reads) in the fourth month's samples, with the proportions of Proteobacteria (34.2\%) and Bacteroidetes (9.2\%) increasing in third month's sample from carcass $\mathrm{A}$. This indicated that bacterial communities in carcass leachates reflected individual variation in the skin or gut microbiota. These results were consistent with those of the diversity index analysis (Figure 1).

These individual differences were further investigated at the

Table 1. Comparison of the abundance of bacterial 165 rDNA sequences in leachates from decomposing bovine carcasses at different sampling times

\begin{tabular}{|c|c|c|c|c|c|c|c|c|}
\hline Items & $\begin{array}{l}\text { Sampling time } \\
\text { (Sample name) }\end{array}$ & $\begin{array}{c}\text { Analyzed } \\
\text { reads }\end{array}$ & $\begin{array}{l}\text { Normalized } \\
\text { reads }\end{array}$ & $\begin{array}{l}\text { Average length } \\
\text { (bp) }\end{array}$ & $\begin{array}{l}\text { Observed } \\
\text { OTUs }\end{array}$ & $\begin{array}{c}\text { Estimated OTUs } \\
\text { (Chao1) }\end{array}$ & $\begin{array}{c}\text { Shannon } \\
\text { index }\end{array}$ & $\begin{array}{c}\text { Good's } \\
\text { coverage }\end{array}$ \\
\hline \multirow[t]{5}{*}{ Carcass A } & Month 1 (A_1) & 7,022 & 3,300 & 467.8 & 964 & $3,971.0$ & 4.20 & 0.76 \\
\hline & Month 2 (A_2) & 11,982 & 3,300 & 433.8 & 263 & 990.5 & 1.36 & 0.94 \\
\hline & Month 3 (A_3) & 3,389 & 3,300 & 471.6 & 513 & $1,759.0$ & 4.07 & 0.89 \\
\hline & Month 4 (A_4) & 5,644 & 3,300 & 479.4 & 256 & 652.0 & 1.93 & 0.95 \\
\hline & Month 5 (A_5) & 8,620 & 3,300 & 461.4 & 393 & $1,477.1$ & 3.37 & 0.91 \\
\hline \multirow[t]{5}{*}{ Carcass B } & Month 1 (B_1) & 3,523 & 3,300 & 458.8 & 495 & $1,723.5$ & 3.80 & 0.89 \\
\hline & Month 2 (B_2) & 3,467 & 3,300 & 457.3 & 490 & $1,785.4$ & 3.39 & 0.89 \\
\hline & Month 3 (B_3) & 6,271 & 3,300 & 470.7 & 296 & $1,021.6$ & 2.64 & 0.93 \\
\hline & Month 4 (B_4) & 12,436 & 3,300 & 477.8 & 428 & $1,988.4$ & 3.32 & 0.90 \\
\hline & Month 5 (B-5) & 7,366 & 3,300 & 472.2 & 578 & $2,853.1$ & 4.07 & 0.86 \\
\hline \multirow[t]{5}{*}{ Carcass C } & Month 1 (C_1) & 2,541 & 2,541 & 468.7 & 296 & 962.3 & 2.90 & 0.92 \\
\hline & Month 2 (C_2) & 6,351 & 3,300 & 472.2 & 458 & $1,665.7$ & 2.62 & 0.90 \\
\hline & Month 3 (C_3) & 4,482 & 3,300 & 472.4 & 228 & 929.4 & 1.84 & 0.95 \\
\hline & Month 4 (C_4)) & 10,723 & 3,300 & 462.1 & 518 & $2,309.3$ & 4.03 & 0.88 \\
\hline & Month 5 (C_5) & 16,625 & 3,300 & 465.7 & 416 & $1,776.0$ & 3.48 & 0.90 \\
\hline
\end{tabular}

OTUs, operational taxonomic units; bp, base pairs. 


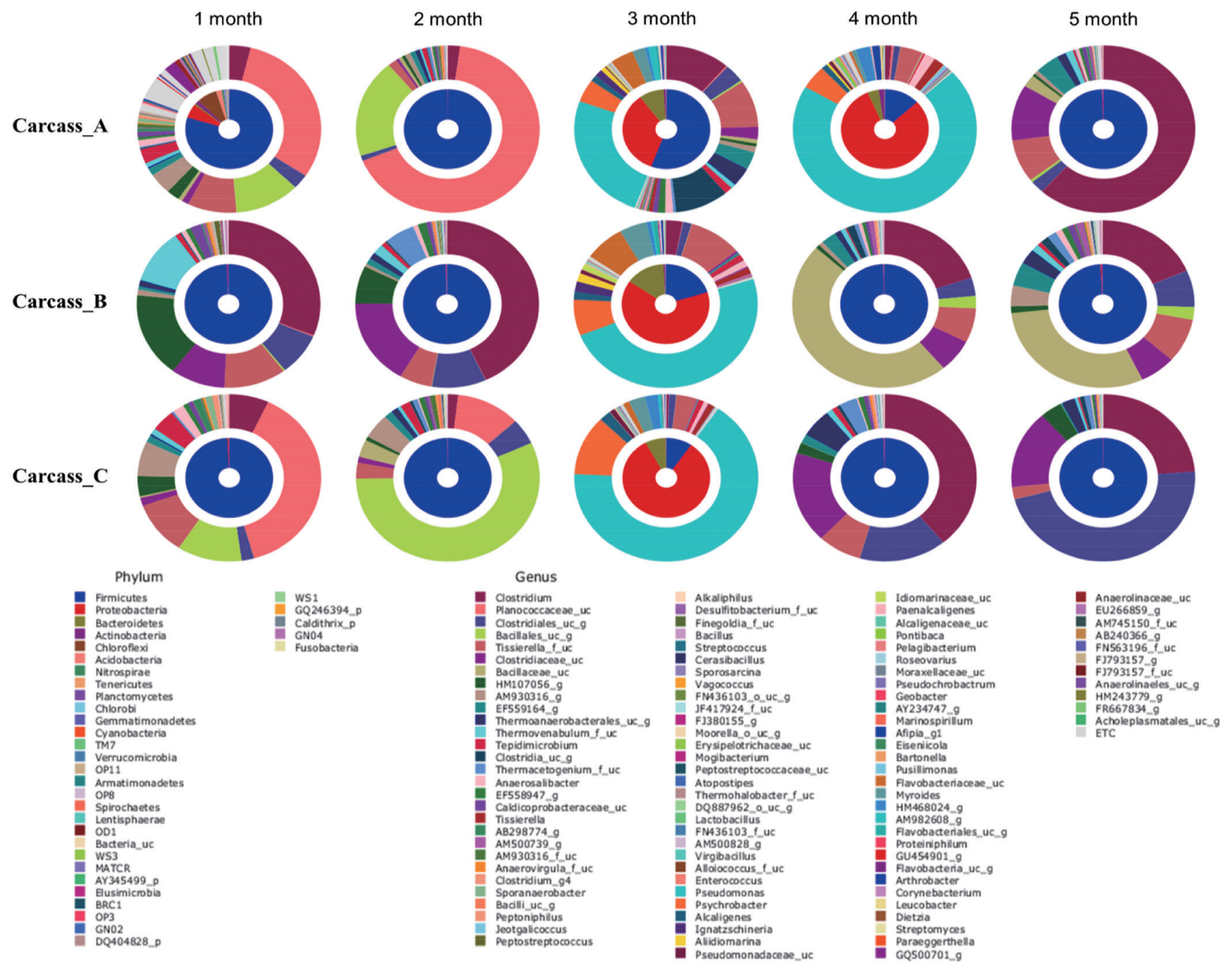

Figure 2. Double pie charts of bacterial communities. The inner and outer pies represent the composition of phyla and genera, respectively. The numbers above each pie indicates the sampling time. The nomenclature of phylotypes is based on the EzTaxon-e database (Kim et al [16]; https://www.ezbiocloud.net/).

genus level (Figure 2). The changes in bacterial phyla from carcasses $\mathrm{B}$ and $\mathrm{C}$ during decomposition were similar, whereas the bacterial genera in leachate samples from these carcasses differed. Clostridium, Clostridiales, and Tissierella were the dominant genera in the samples from carcass B at 1 and 2 months of decomposition. Tissierella is an anaerobic species that reduces proteins and amino acids, and the abundance of these bacteria generally increases with decomposition, whereas Clostridiales play a major role in degradation of protein and cellulose [20,24]. Previous reports have suggested that an anaerobic zone that develops around a carcass during composting is responsible for the increase in Clostridium.

Clostridium spp. play an essential role in biomass digestion by producing a wide variety of extracellular enzymes to degrade large biological molecules [25-27]. However, Planococcaceae was predominant in the sample from carcass $\mathrm{C}$ in the first month, and Bacillales was dominant in the second month. Diverse genera were observed in the carcass A sample after the first month, and Planococcaceae were dominant in the second month's sample.

Studies have shown that Psychrobacter and Pseudomonas play essential roles in fat decomposition [20]. The genera Pseudomonas and Psychrobacter, both Proteobacteria, increased in samples from all three carcasses after 3 months. Clostridium was the most abundant genus of bacteria in the leachate from carcass A after 5 months, Bacillaceae was dominant in the leachate in carcass B after 4 months, and Clostridium and Clostridiales were dominant in the leachate from carcass $\mathrm{C}$ after 4 months.

These differences in the composition of bacterial communities in the leachates from three decomposing carcasses indicated that these communities are, at least in part, defined by the bacteria present in individual Hanwoo.

An investigation of shifts in bacterial communities is important, because leachates from decomposing carcasses reach the adjacent land and surrounding environment. Microorganisms 
affect the balance of the ecosystem through their metabolites [28].

Results of the categorization of bacterial communities by UniFrac and three-dimensional PCoA are shown in Figure 3. The PCoA separated bacterial communities according to the decomposition time, and results suggested that leachates of decomposing Hanwoo shifted throughout incubation and that there were significant changes in bacterial communities after 4 months.

Our present findings indicate continuous shifts in the composition of bacterial communities in leachates from decomposing bovine carcasses. A wide variety of microbes were identified, and the predominant bacteria varied throughout decomposition. The genera Pseudomonas and Psychrobacter were dominant after 3 months in samples from all carcass leachates. Psychrobacter is present in the spoilage microbiota of chilled proteinaceous foods [29].

Bacillaceae, Clostridium, and Clostridiales were predominant after 4 months of decomposition, whereas Planococcaceae was dominant in leachate from samples $\mathrm{A}$ and $\mathrm{C}$ after the first and second month of the sampling period. These continually shifting bacterial communities in leachates might affect the surrounding environment, including soil and groundwater at or near the burial site, and lead to changes in the composition of organic materials, indigenous microbes, and symbionts. In agreement with results of this study, bacterial communities in leachates from decomposing swine carcasses were also shown to change continuously throughout decomposition [12]. These results showed the potential for opportunistic pathogens in burial leachates to multiply during decomposition. These changes in bacterial communities may have adverse effects on public health.

\section{CONCLUSION}

Using high-throughput pyrosequencing and optimized DNA extraction protocols, we characterized the shift of bacterial communities in leachates from decomposing bovine carcasses over 5 months in the present study. Different bacterial groups dominated at specific times during decomposition; Planococcaceae and Bacillales dominated in the first and second month's samples; Thermovenabulum and Tissierella in the third month's samples; Anaerolinaceae, Flavobacteria, and Thermovenabulum in the

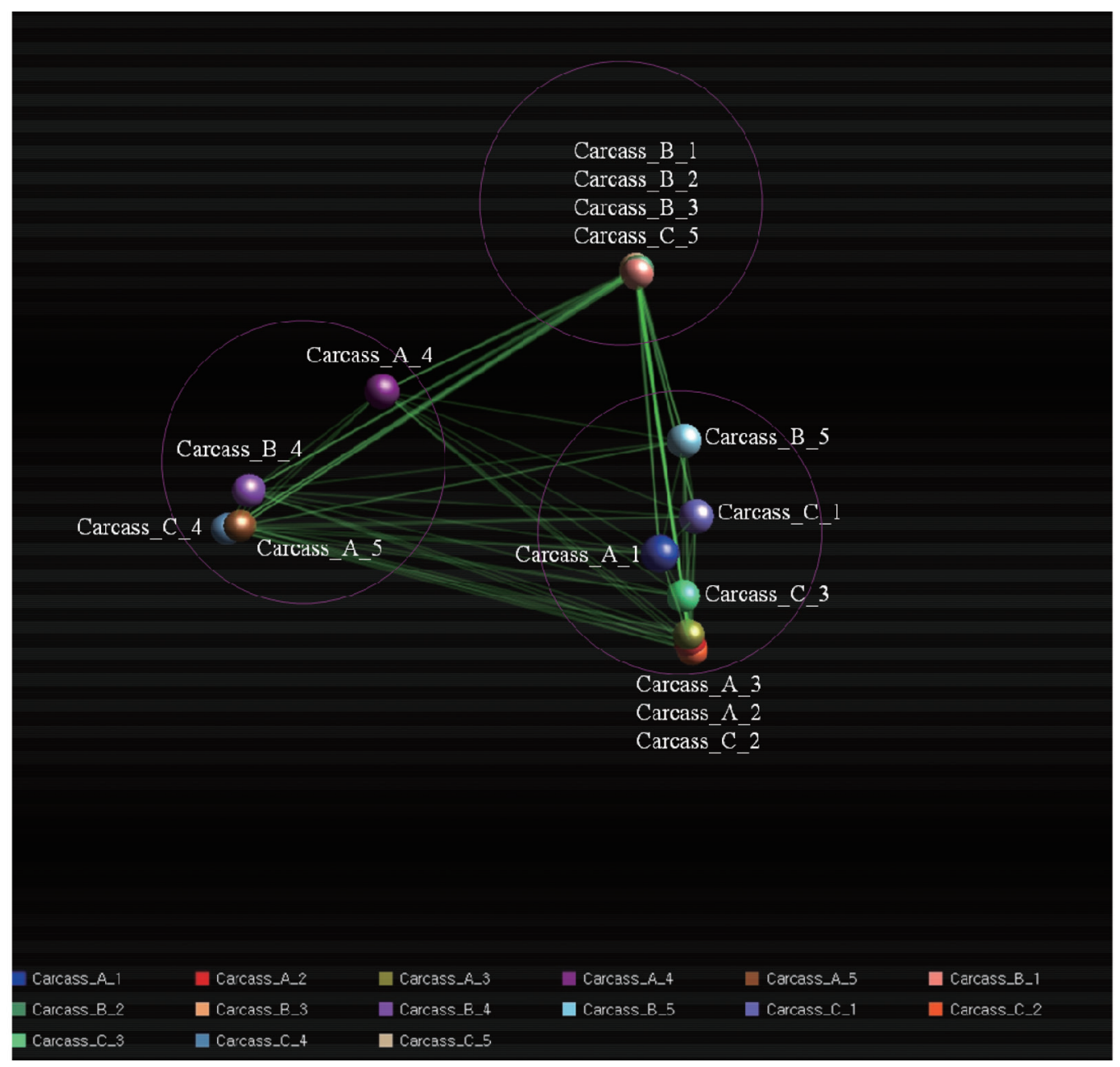

Figure 3. Principal coordinate analysis (PCOA) results showing the relatedness of bacterial community in the different samples. 3D PCoA plots were constructed with the weighted UniFrac distances. 
fourth month's samples; and finally Anaerolinaceae and Flavobacteria in the fifth month's samples. The identification of new bacterial genera involved in bovine carcass decomposition can provide insight into the specific changes in microbial types and quantity during vertebrate decomposition. Therefore, regular monitoring of microbial communities in burial sites should be conducted, because microorganisms can greatly modify ecosystem chemistry through their metabolic activities. In conclusion, our results could be beneficial for maintaining healthy ecosystems and in designing and implementing measures to prevent future outbreaks of FMD or other diseases in Korea. However, further studies of burial sites are required to identify the key points at which microbial community composition changes during decomposition.

\section{CONFLICT OF INTEREST}

We certify that there is no conflict of interest with any financial organization regarding the material discussed in the manuscript.

\section{ACKNOWLEDGMENTS}

This work was carried out with the support of "Cooperative Research Program for Agriculture Science \& Technology Development (Project No. PJ90711004)" Rural Development Administration, Republic of Korea.

\section{REFERENCES}

1.Ahn H. 2010 FMD outbreak in Korea: Government's response to this emergency and important lessons learned. Dearborn, MI, USA: University of Maine; 2012.

2.NRC. Committee on toxins and pathogens in biosolids applied to land: advancing standards and practices. Washington DC, USA: National Research Council; 2002.

3.Brown P. BSE: the final resting place. Lancet 1998;351:1146-7.

4.Nechitaylo TY, Timmis KN, Byzov BA, et al. Fate of prions in soil: degradation of recombinant prion in aqueous extracts from soil and casts of two earthworm species. Soil Biol Biochem 2010;42:1168-71.

5.Vass AA, Bass WM, Wolt JD, Foss JE, Ammons JT. Time since death determinations of human cadavers using soil solution. J Forensic Sci 1992;37:1236-53.

6.Gill-King H. Chemical and ultrastructural aspects of decomposition. In: Haglund WD, Sorg MH, editors. Forensic taphonomy: the postmortem fate of human remains. Boca Raton, FL, USA: CRC Press; 1997.

7.Carter DO, Tibbett M. Microbial decomposition of skeletal muscle tissue (Ovis aries) in a sandy loam soil at different temperatures. Soil Biol Biochem 2006;38:1139-45.

8.Roling WFM, van Breukelen BM, Braster M, Lin B, van Verseveld HW. Relationships between microbial community structure and hydrochemistry in a landfill leachate-polluted aquifer. Appl Environ
Microbiol 2001;67:4619-29.

9. Acosta-Martínez V, Acosta-Mercado D, Sotomayor-Ramírez D, CruzRodríguez L. Microbial communities and enzymatic activities under different management in semiarid soils. Appl Soil Ecol 2008;38:249-60.

10. Keener HM, Elwell DL, Monnin JJ. Procedures and equations for sizing of structures and windrows for composting animal mortalities. Appl Eng Agric 2000;16:681-92.

11. Yang SH, Hong SH, Cho SB, et al. Characterization of microbial community in the leachate associated with the decomposition of entombed pigs. J Microbiol Biotechnol 2012;22:1330-5.

12. Yang SH, Lim JS, Khan MA, et al. High-throughput nucleotide sequence analysis of diverse bacterial communities in leachates of decomposing pig carcasses. Genet Mol Biol 2015;38:373-80.

13. Hamady M, Lozupone C, Knight R. Fast UniFrac: facilitating highthroughput phylogenetic analyses of microbial communities including analysis of pyrosequencing and PhyloChip data. ISME J 2010;4:17-27.

14. Kim BS, Kim JN, Yoon SH, Chun J, Cerniglia CE. Impact of enrofloxacin on the human intestinal microbiota revealed by comparative molecular analysis. Anaerobe 2012;18:310-20.

15. Jeon YS, Chun J, Kim BS. Identification of household bacterial community and analysis of species shared with human microbiome. Curr Microbiol 2013;67:557-63.

16. Kim OS, Cho YJ, Lee K, et al. Introducing EzTaxon-e: a prokaryotic $16 \mathrm{~S}$ rRNA gene sequence database with phylotypes that represent uncultured species. Int J Syst Evol Microbiol 2012;62:716-21.

17. Edgar RC, Haas BJ, Clemente JC, Quince C, Knight R. UCHIME improves sensitivity and speed of chimera detection. Bioinformatics 2011;27:2194-200.

18. Schloss PD, Westcott SL, Ryabin T, et al. Introducing mothur: opensource, platform-independent, community-supported software for describing and comparing microbial communities. Appl Environ Microbiol 2009;75:7537-41.

19. Xu J, Chiang HC, Bjursell MK, Gordon JI. Message from a human gut symbiont: sensitivity is a prerequisite for sharing. Trends Microbiol 2004;12:21-8

20. Li A, Chu YN, Wang X, et al. A pyrosequencing-based metagenomic study of methane-producing microbial community in solid-state biogas reactor. Biotechnol Biofuels 2013;6:3.

21. Sanapareddy N, Hamp TJ, Gonzalez LC, et al. Molecular diversity of a North Carolina wastewater treatment plant as revealed by pyrosequencing. Appl Environ Microbiol 2009;75:1688-96.

22. Poulsen PHB, Al-Soud WA, Bergmark L, et al. Effects of fertilization with urban and agricultural organic wastes in a field trial—prokaryotic diversity investigated by pyrosequencing. Soil Biol Biochem 2013; 57:784-93.

23. Kragelund C, Levantesi C, Borger A, et al. Identity, abundance and ecophysiology of filamentous Chloroflexi species present in activated sludge treatment plants. FEMS Microbiol Ecol 2007;59:671-82.

24. Harms C, Schleicher A, Collins MD, Andreesen JR. Tissierella creatinophila sp. nov., a gram-positive, anaerobic, non-spore-forming, creatinine-fermenting organism. Int J Syst Bacteriol 1998;48 Pt 3: 983-93. 
25. Berge ACB, Glanville TD, Millner PD, Klingborg DJ. Methods and microbial risks associated with composting of animal carcasses in the United States. J Am Vet Med Assoc 2009;234:47-56.

26. Kelch WJ, Kerr LA, Pringle JK, Rohrbach BW, Whitlock RH. Fatal Clostridium botulinum toxicosis in eleven Holstein cattle fed round bale barley haylage. J Vet Diagn Invest 2000;12:453-5.

27. Tracy BP, Jones SW, Fast AG, Indurthi DC, Papoutsakis ET. Clostridia: the importance of their exceptional substrate and metabolite diversity for biofuel and biorefinery applications. Curr Opin Biotechnol 2012; 23:364-81.

28. Stahl DA, Tiedje JM. Microbial ecology and genomics: a crossroads of opportunity. American Academy of Microbiology; 2002. pp. 5-12.

29. Bowman JP, The genus Psychrobacter. In: Dworkin M, Falkow S, Rosenberg E, Schleifer KH, Stackebrandt E, editors. The prokaryotes - a handbook on the biology of bacteria. New York, USA: Springer; 2006. pp. 920-30. 